\title{
Petroleum substitution, greenhouse gas emissions reduction and environmental benefits from the development of natural gas vehicles in China
}

\author{
Jie-Hui Yuan ${ }^{1,2} \cdot$ Sheng Zhou ${ }^{1,2} \cdot$ Tian-Duo Peng ${ }^{1,2} \cdot$ Ge-Hua Wang ${ }^{1,2} \cdot$ Xun-Min Ou ${ }^{1,2}$
}

Received: 28 September 2017 / Published online: 21 June 2018

(c) The Author(s) 2018

\begin{abstract}
This study develops a bottom-up model to quantitatively assess the comprehensive effects of replacing traditional petroleum-powered vehicles with natural gas vehicles (NGVs) in China based on an investigation of the direct energy consumption and critical air pollutant (CAP) emission intensity, life-cycle energy use and greenhouse gas (GHG) emission intensity of NGV fleets. The results indicate that, on average, there are no net energy savings from replacing a traditional fuel vehicle with an NGV. Interestingly, an NGV results in significant reductions in direct CAP and life-cycle GHG emissions compared to those of a traditional fuel vehicle, ranging from $61 \%$ to $76 \%$ and $12 \%$ to $29 \%$, respectively. Due to the increasing use of natural gas as a vehicle fuel in China (i.e. approximately 28.2 billion cubic metres of natural gas in 2015), the total petroleum substituted with natural gas was approximately 23.8 million tonnes (Mt), which generated a GHG emission reduction of $16.9 \mathrm{Mt}$ of $\mathrm{CO}_{2}$ equivalent and a CAP emission reduction of $1.8 \mathrm{Mt}$ in 2015. Given the significant contribution of NGVs, growing the NGV population in 2020 will further increase the petroleum substitution benefits and CAP and GHG emission reduction benefits by approximately $42.5 \mathrm{Mt}$ of petroleum-based fuel, $3.1 \mathrm{Mt}$ of CAPs and 28.0 Mt of GHGs. By 2030, these benefits will reach 81.5 Mt of traditional petroleum fuel, 5.6 Mt of CAPs and 50.5 Mt of GHGs, respectively.
\end{abstract}

Keywords Natural gas vehicles · Energy use $\cdot$ Greenhouse gases · Critical air pollutants · China $\cdot$ Life-cycle analysis

\section{Introduction}

As the global economy has prospered, in particular with the economic progress in developing economies, world energy demands have increased significantly in the past few decades. Due to the heavy utilization of fossil energy, dominated by high-carbon and high-pollution energy sources such as coal and oil, enormous quantities of greenhouse gases (GHGs) and critical air pollutants (CAPs) have been

Edited by Xiu-Qin Zhu

Handling editor: Qi Zhang

Xun-Min Ou

ouxm@mail.tsinghua.edu.cn

1 Institute of Energy, Environment and Economy, Tsinghua University, Beijing 100084, China

2 China Automotive Energy Research Centre, Tsinghua University, Beijing 100084, China released (International Energy Agency (IEA) 2016; IEA 2015). Moving towards a low-carbon and green economy, many countries are increasing their efforts to reduce GHG and CAP emissions from final demand sectors. As a typical representative of the developing countries and one of the largest economies, China is actively seeking to increase the use of relatively low-carbon and cleaner energy sources such as natural gas (NG) (Ma and Li 2010; National Development and Reform Commission (NDRC) and National Energy Administration (NEA) 2016a, b; Yun et al. 2012). Following the development of an energy revolution strategy, a series of policies and plans have indicated that it is necessary to raise the share of NG in primary energy consumption and to develop natural gas into one of the main energy sources in China (NDRC 2016; NDRC and NEA 2016a, b). Among the final consumption sectors in China, the transportation sector is not only a main contributor to oil consumption but is also a main contributor to GHG and CAP emissions (Yang et al. 2016; Ministry of Environmental Protection (MEP) 2017a). 
Table 1 Overview of policies and plans for both NG and NGV development in China

\begin{tabular}{|c|c|c|}
\hline Time & Item $^{\mathrm{a}}$ & References \\
\hline Jun. 2017 & The opinions on accelerating the utilization of natural gas & NDRC et al. (2017) \\
\hline Mar. 2017 & $\begin{array}{l}\text { The action plan on air pollution prevention and control in the Beijing-Tianjin-Hebei region } \\
\text { and the surrounding areas in } 2017\end{array}$ & MEP et al. (2017) \\
\hline Jan. 2017 & $\begin{array}{l}\text { The comprehensive work plan for energy conservation and emission reduction during the } \\
\text { 13th Five-Year Plan period }\end{array}$ & State Council (SC) (2017) \\
\hline Dec. 2016 & The 13th Five-Year Plan for energy development & NDRC and NEA (2016a) \\
\hline Dec. 2016 & The 13th Five-Year Plan for natural gas development & NDRC (2016) \\
\hline Dec. 2016 & The strategy for energy production and consumer revolution (2016-2030) & NDRC and NEA (2016b) \\
\hline Jun. 2014 & The strategy action plan for energy development (2014-2020) & SC (2014) \\
\hline Sep. 2014 & The national plan on climate change (2014-2020) & NDRC (2014) \\
\hline Sep. 2013 & The action plan for air pollution prevention and control & SC (2013) \\
\hline
\end{tabular}

${ }^{a}$ Because the number of policies and plans issued for both NG and NGV development in China is very high, the key policies and plans issued in the past few years are presented here

Because NG is clean burning and confers power supply advantages, NG fuel is a viable alternative to traditional gasoline/diesel fuel (Hao et al. 2016; Khan et al. 2015; Osorio-Tejada et al. 2015). In recent years, China has increased its efforts to reduce transportation emissions and to reduce the dependence on foreign oil by using NG fuel and by developing natural gas vehicles (NGVs) (see Table 1). Remarkable progress has been made in the development of NGVs in China (see Fig. 1).

Life-cycle analysis (LCA) is a useful modelling tool for quantitatively estimating the energy consumption, environmental emissions and economic effects resulting from the use of alternative fuels and vehicle technologies. Numerous studies have been conducted to investigate the fuel consumption and GHG emissions of alternative vehicle technologies from the life-cycle perspective (Ou et al. 2012; Xu et al. 2015). However, the number of published LCA studies on vehicles using alternative fuels such as NG is relatively small. These studies have focused on LCA studies on NGVs in China from the perspective of alternative fuels, highlighting a wide range of alternatives and analysing fuel pathways (Kliucininkas et al. 2012; Ou and Zhang 2013; Shen et al. 2012). Moreover, most previous studies have conducted an LCA of one or two types of NGVs, such as light-duty passenger vehicles or heavy-duty commercial vehicles (buses or trucks) (Hao et al. 2013; Tu et al. 2013a, b; Ou et al. 2013). Hao et al. (2013) conducted an LCA to estimate the future trends in fuel consumption and life-cycle GHG emissions for on-road trucks in China and emphasized that if the share of liquefied natural gas (LNG) powered trucks in all newly registered semi-trailer towing trucks and heavy-duty trucks is increased to $20 \%$ in 2030, an estimated $7.9 \%$ and $10.9 \%$ of the total diesel consumption by trucks will be replaced by LNG in 2030 and 2050, respectively. In another study, Tu et al. (2013b)

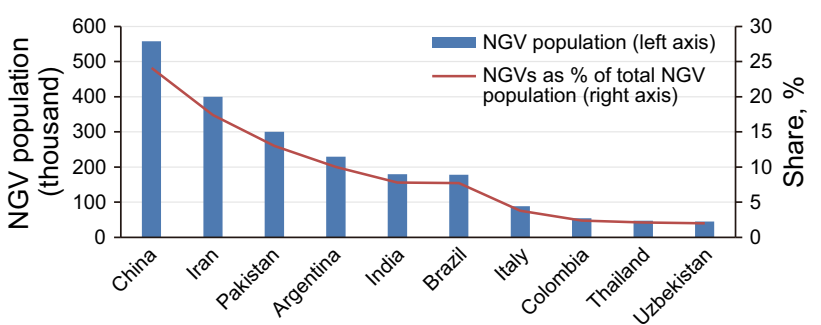

Fig. 1 Countries with the top $10 \mathrm{NGV}$ populations in the world in 2016 Source: based on China Automotive Technology and Research Center (CATARC) Beijing Operations (2017), Ma et al. (2013) and NGV Global (2017)

evaluated the life-cycle emissions of GHGs and other pollutants from concrete-mixer trucks (a typical type of trucks) powered by diesel and LNG. The use of LNG was suggested to result in a $9 \%$ reduction in GHG emissions compared with diesel, whereas other pollutants varied. As demonstrated by Ou et al. (2013), a life-cycle model is used to assess the GHG emissions of vehicles powered by NGbased fuels and to assess the electric vehicles (EVs) powered with NG-to-electricity in China. From the life-cycle perspective, NG electricity-powered EV and NGV pathways can decrease the life-cycle GHG emissions compared to vehicles powered by petroleum-based gasoline by $42 \%$ and $10 \%$, respectively. In addition, few previous studies have focused on the quantitative evaluation of petroleum substitution effects of $\mathrm{NGV}$ fleets considering multiple types of NGVs in China (Jiao et al. 2017; Niu et al. 2017). Jiao et al. (2017) constructed a conceptual model of substituting automotive fuels and an evaluation model to investigate the substitutive effects of three kinds of substitutive policies in the Chinese transportation industry: NG, ethanol and methanol. They concluded that these three substitutive policies can significantly reduce the cost of oil dependence, and they suggested that China should promote 
an NG alternative policy in the short term. In another study, Niu et al. (2017) evaluated the impact of the development of alternative energy such as gas vehicles, new energy vehicles and biomass fuel on the petroleum demand in China.

Most studies on the CAP emissions of NGVs in China also focus on one or two types of NGVs rather than conducting a comprehensive study on NGV fleets (Rose et al. 2013; Yao et al. 2009). Rose et al. (2013) conducted a comparative LCA of GHGs and other pollutants from heavy-duty refuse collection trucks powered by diesel and compressed natural gas (CNG) in a Canadian city. The authors emphasized that $\mathrm{CNG}$ heavy-duty refuse collection trucks can offer an advantage in terms of reduced environmental impacts and cost savings. Another study conducted by Yao et al. (2009) adopted an analytic hierarchy process (AHP) method to perform an evaluation of NGVs (dominated by buses and taxis) in Sichuan Province. The analysis demonstrated that developing NGVs is one of the more effective ways to control oil consumption and air pollution and realize sustainable social and economic development.

Therefore, there is a gap in the knowledge regarding the complete evaluation of petroleum substitution, GHG reduction and CAP reduction benefits of NGV fleets considering the multiple types of NGVs in China. The current study focuses on establishing a bottom-up model to quantitatively assess the comprehensive effect of replacing traditional petroleum-powered vehicles with NGVs in China through an investigation of the direct energy consumption, CAP emissions intensity, life-cycle energy use and GHG emissions intensity of NGV fleets. This study offers four major areas of analysis compared to past studies on NGVs. First, this study establishes a bottom-up model to assess NGVs by considering six segments based on an integrated computing platform. Second, unlike the previous studies, this study adopts real data for key parameters to conduct a systematic and comprehensive analysis of the direct energy consumption, life-cycle energy use, GHG emissions and direct CAP emissions of NGVs. Third, the study explored the comprehensive effects of using $\mathrm{NG}$ instead of gasoline or diesel to power vehicles, including the petroleum substitution effect, CAP reduction effect and GHG reduction effect. Fourth, the analysed objects include an NGV and country-level NGV fleets. Finally, a life-cycle fuel inventory database derived from the TLCAM, which is used to conduct the LCA, is specified for the context of China. With these improvements, this study conducts a holistic and comprehensive study on $\mathrm{NGV}_{\mathrm{s}}$ and comparable traditional fuel vehicles in China by comparing their energy use, GHG emissions and CAP emissions to contribute to decision-making by the government, enterprises and the public.
The aim of this study was to quantitatively assess the comprehensive effects achieved by replacing traditional fuel vehicles with NGVs in China by utilizing actual, reliable data. This information can help identify the potential for expanding the use of NGVs to realize China's targets for the reduction of the dependence on foreign oil and GHG and CAP emissions. The findings of this study will allow decision-makers in countries pursuing low-carbon and sustainable development to make informed decisions when promoting the development of $\mathrm{NGV}_{\mathrm{s}}$ based on realistic estimations of energy use and environmental emissions. The remainder of article is structured as follows. Section 2 introduces the methods adopted, including the model and the calculation equations. Section 3 mainly describes the assumptions and data adopted for this study. Section 4 presents the results and provides some discussion. Section 5 presents the main conclusions and highlights the key aspects of this work.

\section{Methods}

\subsection{Boundaries}

To analyse the energy use and GHG emissions of NGVs in China, a bottom-up calculation method is used on six segments of NGVs with an LCA method using the Tsinghua-LCA Model (TLCAM). The TLCAM was developed by the China Automotive Energy Research Centre, Tsinghua University, and is based on the GREET model, which is a well-known LCA tool (Ou et al. 2013; Ou and Zhang 2013). This model is a Chinese life-cycle modelling tool for evaluating the lifetime energy consumption and GHG emissions of alternative transportation fuels and vehicle technologies. The life-cycle stages of the fuel include energy extraction/transport, fuel production/transport and fuel use. A bottom-up model derived from the TLCAM is developed to investigate the direct energy consumption, life-cycle energy use and GHG emissions for petroleum and NG vehicles in China. In this LCA, C1 denotes the energy extraction sub-stage; $\mathrm{C} 2$ is the energy transport substage; C3 is the fuel production sub-stage; $\mathrm{C} 4$ is the fuel transport sub-stage; and C5 is the fuel-use sub-stage.

With the help of the iterative and source-tracing functions of the TLCAM, all of the fuels and energy used in the various sub-stages can be converted into the use of three types of primary fossil energy (raw coal, raw NG and petroleum). In this study, GHG emissions include carbon dioxide $\left(\mathrm{CO}_{2}\right)$, methane $\left(\mathrm{CH}_{4}\right)$, and nitrous oxide $\left(\mathrm{N}_{2} \mathrm{O}\right)$, which are the most important GHGs. The global warming potential (GWP) in $\mathrm{CO}_{2}$ equivalents (i.e. $\mathrm{CO}_{2 \text {-equivalent }}$ $\left(\mathrm{CO}_{2, \mathrm{e}}\right) \mathrm{GHG}$ emissions) was calculated assuming a 100-year time horizon (Intergovernmental Panel on 
Climate Change (IPCC) 2007; Shahraeeni et al. 2015). According to the Intergovernmental Panel on Climate Change (IPCC) report, the GWPs for $\mathrm{CO}_{2}, \mathrm{CH}_{4}$ and $\mathrm{N}_{2} \mathrm{O}$ are 1, 25 and 298, respectively. For each vehicle type, the model computes the primary energy demand (MJ) and the GHG emissions ( $\mathrm{g} \mathrm{CO}_{2, \mathrm{e}}$ ).

In addition, the assessment of the CAP emissions intensity of NGVs in China should employ an emission factor method such as that used in Xing et al. (2016) and Yao et al. (2009). In this study, the CAPs include hydrocarbon compounds ( $\mathrm{HC})$, carbon monoxide $(\mathrm{CO})$, nitrogen oxides $\left(\mathrm{NO}_{\mathrm{x}}\right)$, sulphur dioxide $\left(\mathrm{SO}_{2}\right)$ and particulate matter (PM, $\mathrm{PM}_{2.5}$ specifically). Given the contribution of the vehicle population and CAP emissions, the petroleumpowered vehicles in this study fall under the national standard III (MEP 2017b).

According to investigations and surveys, the largest share of the NGV population in China comprises $\mathrm{CNG}$ taxis, other CNG passenger vehicles (PVs), CNG buses, CNG trucks (light duty, LDT), LNG buses and LNG trucks (heavy duty, HDT). Moreover, the majority of CNG trucks are light-duty trucks (LDTs), i.e. CNG LDTs. Most LNG trucks are HDTs, i.e. LNG HDTs. In this study, the NGVs in China include the above six types of vehicles.

\subsection{Methodology}

This study establishes a bottom-up model to assess the total direct energy consumption and CAP emissions, life-cycle energy use and GHG emissions of on-road diesel/gasoline and NG vehicles in China. The structure of the model is illustrated in Fig. 2.

\subsubsection{Fuel consumption calculation of NGV operation and the accompanying petroleum substitution benefit}

Based on the fuel consumption rate and annual distance travelled of NGVs in China and the calorific value of each fuel utilized in NGVs, the annual amount of fuel consumed to operate an NGV can be calculated. For the data obtained, the fuel consumption to operate an NGV in China is calculated as in Eq. (1):

$\mathrm{EC}_{i, j}=\mathrm{FE}_{i, j} \times \mathrm{ADT}_{j} \times \mathrm{LCV}_{i}$

where $\mathrm{EC}_{i, j}$ is the annual energy consumed to operate an $\mathrm{NGV}$ for different applications types in China (MJ); $i$ is the fuel type used in the NGV (see Tables 2 and 3); $j$ is the application type of the $\mathrm{NGV}(j=1,2, \ldots, 4) ; \mathrm{FE}_{i, j}$ is the fuel consumption rate of $\mathrm{NGVs}$ for different application types $(\mathrm{L} / 100 \mathrm{~km}) ; \mathrm{ADT}_{j}$ is the annual distance travelled by vehicles for different application types $(100 \mathrm{~km})$; and $\mathrm{LCV}_{i}$ is the low calorific value of each type of fuel utilized in NGVs (MJ/L).

By combining the energy consumption of an NGV with the population of NGVs by year, the energy consumed to operate NGVs in China can be calculated. Based on the data obtained, the energy consumed per year by NGV fleets operating in China is calculated as in Eq. (2):

$\mathrm{EC}_{i, t}=\sum_{i=1}^{k}\left(\sum_{j=1}^{k} \mathrm{EC}_{i, j} \times \mathrm{VP}_{i, j, t}\right)$

where $\mathrm{EC}_{i, t}$ is the annual energy consumption of $\mathrm{NGV}$ fleets with different application types in China in year $t$ (MJ); $k$ is 2 (when comparing NGVs with gasoline vehicles) or 3 (when comparing NGVs with diesel vehicles); and $\mathrm{VP}_{i, j, t}$ is the population of NGVs with different application types in China in year $t$ (thousands). Based on Eq. (2), the accompanying petroleum substitution benefit from replacing traditional fuel vehicles with $\mathrm{NGVs}$ in China can be calculated.

\subsubsection{Calculating the CAP emissions of NGVs in China}

Based on the CAP emissions factors, annual distance travelled and population of NGVs in China, the annual CAP emissions of NGVs can be identified. For the data obtained, the CAP emissions of NGVs in China are calculated as in Eq. (3):

$\mathrm{CAP}_{i, t}=\sum_{i=1}^{k}\left(\sum_{j=1}^{k} \mathrm{APEF}_{i, j} \times \mathrm{ADT}_{j} \times \mathrm{VP}_{i, j, t}\right)$

where $\mathrm{CAP}_{i, t}$ represents the annual CAP emissions of NGVs with different application types operating in China (thousand tonnes) and $\mathrm{APEF}_{i, j}$ represents the CAP emission factors of NGVs with different application types operating in China $(\mathrm{mg} / \mathrm{km})$. Based on Eq. (3), the CAP emissions reduction benefits from replacing traditional fuel vehicles with NGVs in China can be calculated.

\subsubsection{Calculating the energy use of NGVs in China}

After the life-cycle primary energy consumption factors for the fuel used in NGVs are determined, the energy use of NGVs in China can be identified. For the data obtained, the life-cycle energy use of an NGV is calculated as in Eq. (4):

$\mathrm{LCEC}_{i, j}=\mathrm{EC}_{i, j} \times \mathrm{PECF}_{i}$

where $\mathrm{LCEC}_{i, j}$ is the life-cycle energy consumption of an NGV operating in China with type $j$ application (MJ) and $\mathrm{PECF}_{i}$ is the life-cycle primary energy consumption factor for the fuel life cycle of an NGV using type $i$ fuel (MJ/MJ). 

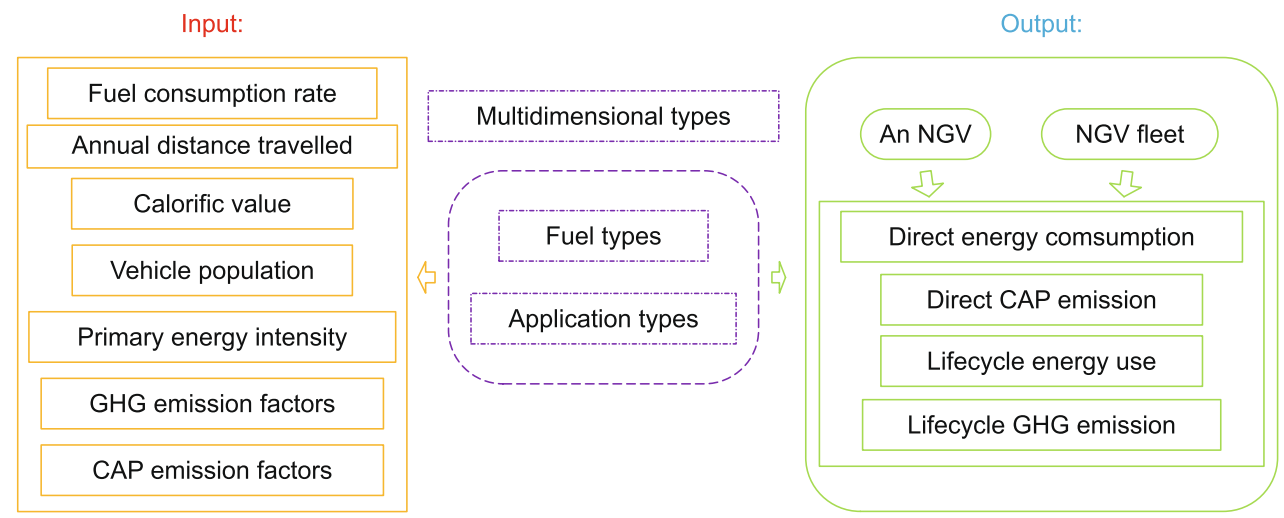

Fig. 2 Diagram of model structure

Table 2 Interpretation of $i$ and $j$ when comparing NGVs with gasoline vehicles

\begin{tabular}{lll}
\hline No. & Fuel type & $\begin{array}{l}\text { Application type } \\
i\end{array}$ \\
\hline 1 & Gasoline & Taxi \\
2 & CNG & Other PVs
\end{tabular}

Table 3 Interpretation of $i$ and $j$ when comparing NGVs with diesel vehicles

\begin{tabular}{lll}
\hline No. & Fuel type & Application type \\
& $i$ & $j$ \\
\hline 1 & Diesel & Bus \\
2 & $\mathrm{CNG}^{\mathrm{a}}$ & LDT \\
3 & LNG & HDT \\
\hline
\end{tabular}

${ }^{\mathrm{a}}$ In this study, NG trucks include only CNG LDTs and LNG HDTs

Combining Eq. (3) with the population of NGVs per year in China, the energy consumption of NGVs in China per year is calculated as in Eq. (5):

$\operatorname{LCEC}_{i, t}=\sum_{i=1}^{k}\left(\sum_{j=1}^{k} \operatorname{LCEC}_{i, j} \times \mathrm{VP}_{i, j, t}\right)$

where $\mathrm{LCEC}_{i, t}$ is the annual energy consumption of NGVs in China in year $t(\mathrm{MJ})$.

\subsubsection{Calculating GHG emissions of NGVs in China}

Having determined the life-cycle GHG emissions factor for the fuel used in NGVs in China, the GHG emissions can now be investigated. For the data obtained, the life-cycle GHG emissions of an NGV in China are calculated as in Eq. (6):

$\mathrm{LCGE}_{i, j}=\mathrm{EC}_{i, j} \times \mathrm{GEF}_{i}$ where $\mathrm{LCEC}_{i, j}$ is the life-cycle GHG emissions of an NGV using type $i$ fuel with type $j$ application operated in China $\left(\mathrm{g} \mathrm{CO}_{2, \mathrm{e}}\right) ; \mathrm{GEF}_{i}$ is the GHG emissions factor of an NGV using type $i$ fuel (g/MJ).

Combining Eq. (5) with the population of NGVs per year in China, the GHG emissions of NGVs in China can be calculated. Based on the data obtained, the GHG emissions of NGVs in China per year are calculated as follows:

$\mathrm{LCGE}_{i, t}=\sum_{i=1}^{k} \sum_{j=1}^{k} \operatorname{LCGE}_{i, j} \times \mathrm{VP}_{i, j, t}$

where $\mathrm{LCGE}_{i, t}$ is the annual GHG emissions of NGVs powered by type $i$ fuel for different application types in China in year $t\left(\mathrm{~g} \mathrm{CO}_{2, \mathrm{e}}\right)$. Based on Eq. (7), the GHG emissions reduction benefits from substituting traditional fuel vehicles with NGVs in China can be calculated.

\section{Data and assumptions}

Seven key data components are required to calculate the desired results of this study: (1) the fuel consumption rate of NGVs in China; (2) the annual distance travelled; (3) the low calorific value of each type of fuel/energy used; (4) the CAP emissions factors of NGVs; (5) the primary energy intensity of the fuel life cycles; (6) the GHG emissions factors of the fuel life cycles; and (7) the population of onroad NGVs.

The primary data used for the evaluation are obtained from real data through a series of investigations and surveys. The data for the fuel consumption rate and CAP emission factors for NGVs in China with different application types are presented in Table 4.

The fuel consumption rate in this study is the specific fuel consumption for NGVs to travel $100 \mathrm{~km}$. The major 
Table 4 Fuel consumption rate and CAP emission factors for NGVs. Source: based on CATARC Beijing Operations (2017), MEP (2016b), Wang (2015) and Yang and Teng (2018)

\begin{tabular}{llllllll}
\hline Application type & Fuel type & $\begin{array}{l}\text { Fuel consumption, } \\
\text { L/100 km }\end{array}$ & \multicolumn{2}{l}{ Air pollutant emission, $\mathrm{mg} / \mathrm{km}$} & \\
\cline { 5 - 8 } & & & $\mathrm{HC}$ & $\mathrm{CO}$ & $\mathrm{NO}_{x}$ & $\mathrm{SO}_{2}$ & $\mathrm{PM}$ \\
\hline Taxi and other PV & Gasoline & 8.7 & 580 & 5800 & 210 & 20 & 10 \\
& CNG & 34.8 & 266.8 & 1160 & 186.9 & $0^{\mathrm{a}}$ & 0.4 \\
\multirow{2}{*}{ Bus } & Diesel & 32.9 & 3560 & 25,330 & 9600 & 40 & 850 \\
& CNG & 191.2 & 1139.2 & 5825.9 & 8256 & 0 & 27 \\
& LNG & 61.3 & 1139.2 & 5825.9 & 8256 & 0 & 27 \\
LDT & Diesel & 18.7 & 550 & 4730 & 470 & 20 & 100 \\
& CNG & 108.0 & 236.5 & 1040.6 & 408.9 & 0 & 3 \\
HDT & Diesel & 36.0 & 2828 & 20,107 & 12,100 & 40 & 1071 \\
& LNG & 66.3 & 905 & 4624.6 & 10,406 & 0 & 30 \\
\hline
\end{tabular}

${ }^{\mathrm{a}}$ Because these values are very small, they are assigned a value of zero

Table 5 Major usage characteristics of NGVs in China. Source: based on CATARC Beijing Operations (2017), Hao et al. (2015) and Xing et al. (2016)

\begin{tabular}{llllll}
\hline Annual distance travelled (ADT) $(100 \mathrm{~km})$ & CNG Taxi & Other CNG PV & Bus (CNG/LNG) & CNG LDT & LNG HDT \\
\hline Low ADT & 1155 & 150 & 627 & 400 & 1150 \\
Average ADT & 1320 & 171 & 726 & 500 & 1337.5 \\
High ADT & 1485 & 192 & 825 & 600 & 1525 \\
\hline
\end{tabular}

travel characteristics for NGVs in China are listed in Table 5.

Table 6 shows the primary energy consumption factors and GHG emission factors which can be used to calculate the life-cycle energy use and GHG emissions of NGVs. To investigate the energy consumption and environmental emission of NGV fleets in China, the vehicle population data is also very important. The population of NGVs with different application types in China is displayed in Table 7.

To calculate the fuel use of NGVs in terms of energy, the calorific value of the fuel is required. Different fuels have different calorific values that estimate the energy they contain. Usually, energy is reflected by the calorific value of each fuel. In this study, the calorific values of gasoline, diesel, CNG and LNG fuel are 31.87, 35.83, 7.12 and $21.35 \mathrm{MJ} / \mathrm{L}$, respectively (British Petroleum (BP) 2016; Huo et al. 2012). In addition, the density of gasoline and diesel fuel is 0.74 and $0.84 \mathrm{~kg} / \mathrm{L}$ (BP 2016; National Bureau of Statistics (NBS) 2016).

\section{Results and discussion}

\subsection{The fuel consumption of NGVs and accompanying petroleum substitution benefit}

Figure 3 shows the energy consumption of NGVs in China and that of corresponding traditional fuel vehicles. Given that the value of the annual distance travelled is a range (see Table 5), the result of annual energy consumption (MJ) by an NGV is also a range. On average, the annual energy consumption of a CNGV is approximately $10.6 \%$ lower than that of a comparable gasoline vehicle. However, the annual energy consumption of a CNG/LNG vehicle is on average approximately $13.0 \%$ higher than that of a comparable diesel vehicle. In general, the annual energy consumption of an NGV is significantly higher than that of a comparable traditional fuel vehicle. This finding also means that NGV technology needs to be improved to reduce fuel consumption and energy use.

Figure 4 illustrates the petroleum substitution benefit of the use of an NGV in 2015. An NGV results in significant reductions in petroleum consumption compared to the petroleum consumed by a gasoline/diesel vehicle, ranging from 1.2 to 8.9 tonnes and 20.3 to 40.8 tonnes, respectively. The overall NG consumption of NGVs and the amount of traditional fuel being replaced in China in 2015 are presented in Fig. 5. Approximately 28.2 billion cubic metres $\left(\mathrm{m}^{3}\right)$ of NG were used in the NGV fleet in 2015, serving as a substitute for approximately $23.0 \mathrm{Mt}$ of petroleum-based fuel, which is $7.9 \%$ of the petroleum-based fuel consumed in China. 
Table 6 Primary energy intensity and GHG emission factors of fuel life cycles in China. Source: based on Ou et al. (2012), (2013) and $\mathrm{Ou}$ and Zhang et al. (2013)

\begin{tabular}{|c|c|c|c|c|}
\hline Types & Gasoline & Diesel & $\mathrm{CNG}$ & LNG \\
\hline \multicolumn{5}{|c|}{ Based on the composition of fossil energy } \\
\hline \multicolumn{5}{|c|}{ Fossil energy use, $\mathrm{MJ} / \mathrm{MJ}$} \\
\hline Coal & 0.079 & 0.077 & 0.08 & 0.127 \\
\hline Oil & 1.159 & 1.152 & 0.008 & 0.015 \\
\hline NG & 0.055 & 0.054 & 1.124 & 1.124 \\
\hline Total & 1.293 & 1.283 & 1.211 & 1.266 \\
\hline \multicolumn{5}{|c|}{ GHG emission, $\mathrm{g} / \mathrm{MJ}$} \\
\hline $\mathrm{CO}_{2}$ & 88.947 & 92.896 & 70.560 & 75.631 \\
\hline $\mathrm{CH}_{4}$ & 0.129 & 0.052 & 0.110 & 0.133 \\
\hline $\mathrm{N}_{2} \mathrm{O}$ & $0^{\mathrm{a}}$ & 0.028 & 0 & 0 \\
\hline Total & 92.17 & 94.20 & 73.40 & 78.95 \\
\hline \multicolumn{5}{|c|}{ Based on life-cycle stage } \\
\hline \multicolumn{5}{|c|}{ Fossil energy use, MJ/MJ } \\
\hline $\mathrm{C} 1^{\mathrm{b}}$ & 0.121 & 0.120 & 0.125 & 0.125 \\
\hline $\mathrm{C} 2$ & 0.019 & 0.019 & 0.003 & 0 \\
\hline $\mathrm{C} 3$ & 0.147 & 0.138 & 0.084 & 0.135 \\
\hline $\mathrm{C} 4$ & 0.007 & 0.007 & 0 & 0.007 \\
\hline \multicolumn{5}{|c|}{ GHG emission, g/MJ } \\
\hline $\mathrm{C} 1$ & 9.06 & 1.53 & 11.08 & 0.58 \\
\hline $\mathrm{C} 2$ & 9.00 & 1.52 & 10.40 & 0.58 \\
\hline $\mathrm{C} 3$ & 9.36 & 0.20 & 7.42 & 0.00 \\
\hline $\mathrm{C} 4$ & 9.35 & 0.00 & 11.99 & 0.48 \\
\hline
\end{tabular}

${ }^{\mathrm{a} B e c a u s e}$ these values are very small, they are assigned a value of zero

${ }^{\mathrm{b}} \mathrm{C} 1, \mathrm{C} 2, \mathrm{C} 3, \mathrm{C} 4$ and $\mathrm{C} 5$ represent the life-cycle sub-stages, i.e. energy extraction, energy transport, fuel production, fuel transport and fuel use

\subsection{CAP emissions reduction benefits from increasing the use of NGVs}

The estimated annual CAP emissions of NGVs and comparable traditional fuel vehicles in China are illustrated in Fig. 6. Similarly, given that the value of the annual distance travelled is a range, the result of CAP emissions from an NGV is also a range. On average, the emission intensity of a given NGV is distinctly lower than that of a comparable traditional fuel vehicle. In 2015, the CAP emission reduction due to increasing the use of NGVs in China was

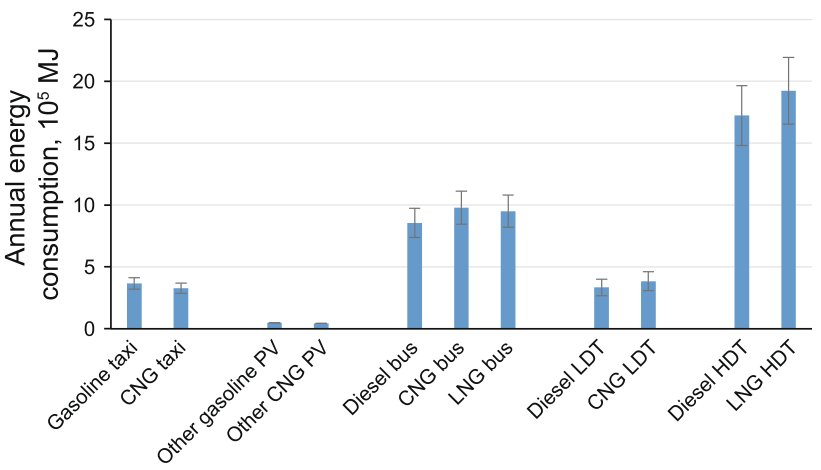

Fig. 3 Direct energy use of NGVs and comparable traditional fuel vehicles in China

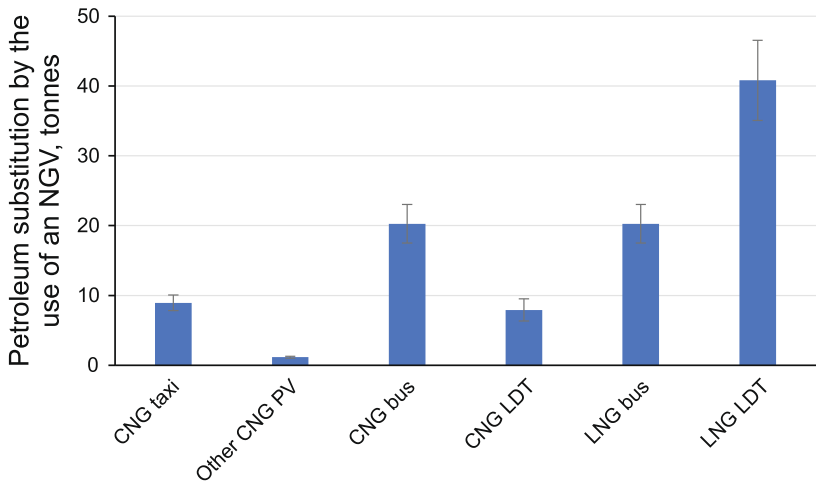

Fig. 4 Annual petroleum substitution by the use of an NGV in 2015

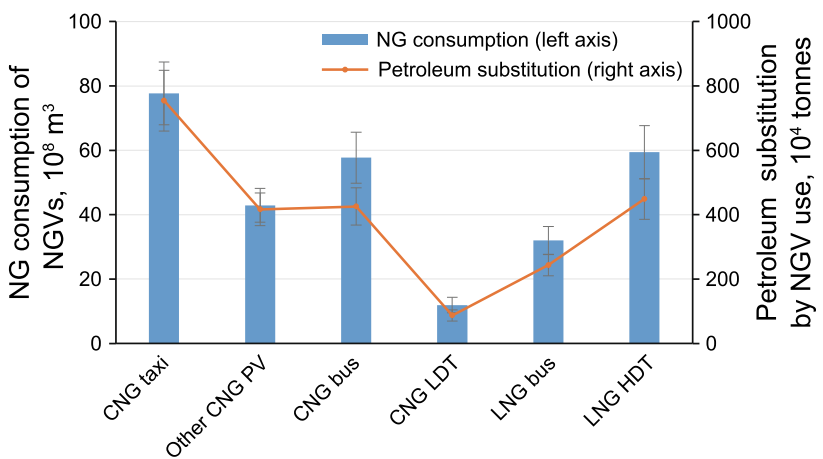

Fig. 5 NG consumption of classified NGV fleets and accompanying petroleum substitution in 2015

$1.77 \mathrm{Mt}$, including $0.14 \mathrm{Mt}$ of $\mathrm{HC}, 1.52 \mathrm{Mt}$ of $\mathrm{CO}, 0.06 \mathrm{Mt}$ of $\mathrm{NO}_{x}, 0.001 \mathrm{Mt}$ of $\mathrm{SO}_{2}$ and $0.04 \mathrm{Mt}$ of PM (presented in Fig. 7). The biggest contribution of emission reduction

Table 7 Classification of the population of NGVs in China by 2015. Source: based on CATARC Beijing Operations (2017), China National Petroleum Corporation (CNPC) Economics and Technology Research Institute (ETRI) (2016) and Li (2017)

\begin{tabular}{lllllll}
\hline NGV type & CNG taxi & Other CNG PV & CNG bus & CNG LDT & LNG bus & LNG LDT \\
\hline Population (thousands) & 845 & 3605 & 210 & 110 & 120 & 110 \\
\hline
\end{tabular}




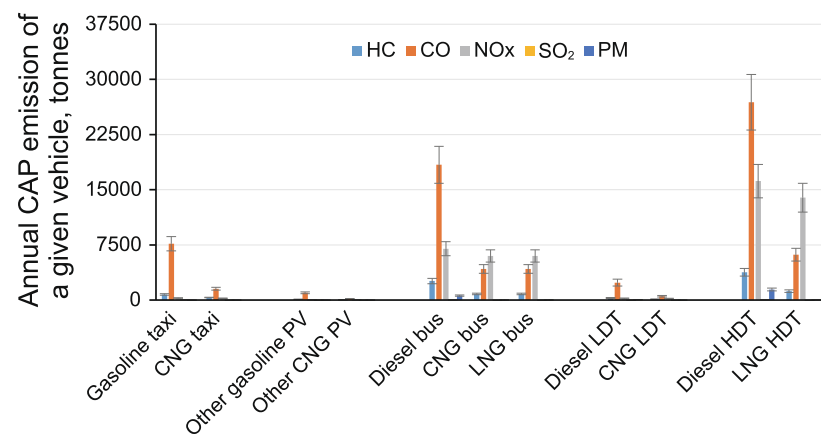

Fig. 6 Annual CAP emission of NGVs and comparable traditional fuel vehicles in China

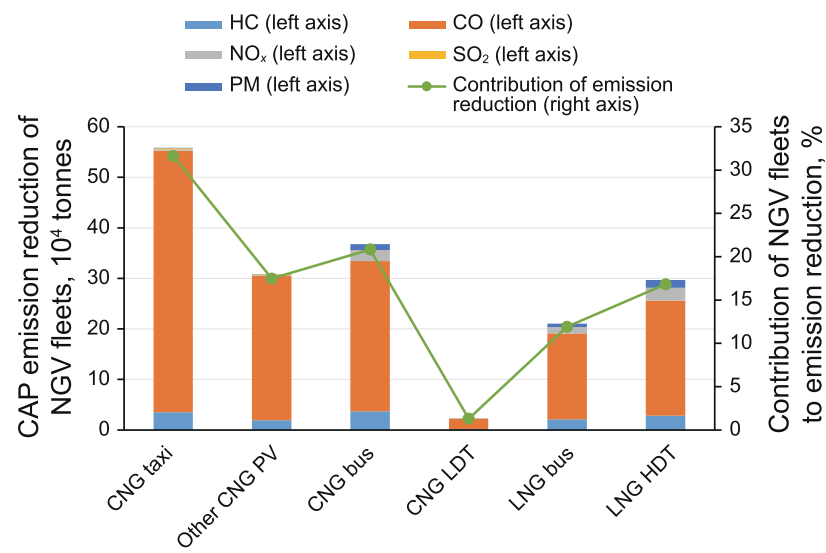

Fig. 7 CAP emissions reduction effect of classified NGV fleets in China

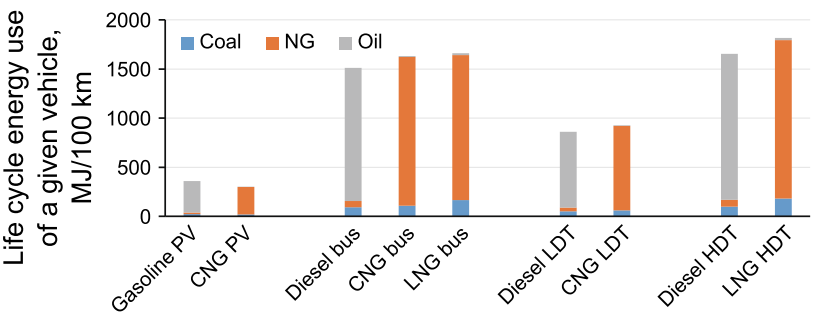

Fig. 8 Life-cycle energy use by primary energy type for NGVs and comparable traditional fuel vehicles in China

generated by classified NGV fleets was from CNG taxis, which resulted in an emissions reduction of $0.56 \mathrm{Mt}$ of CAPs.

\subsection{Life-cycle energy use results for NGVs}

Figure 8 illustrates the life-cycle primary energy use based on the composition of fossil energy for NGVs and comparable traditional fuel vehicles in China. From a life-cycle perspective, the primary energy use of a given NGV is also comparable to a traditional fuel vehicle. In addition to the

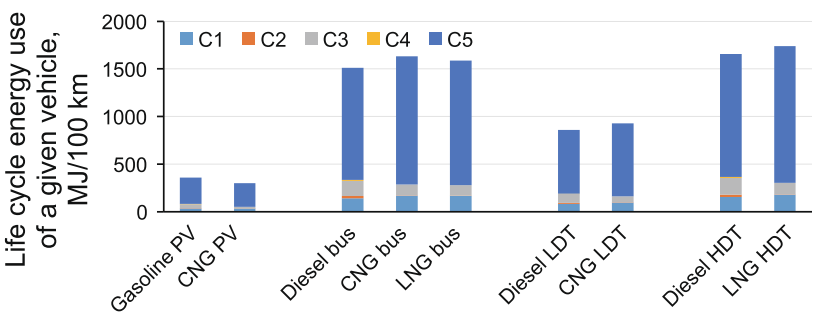

Fig. 9 Life-cycle energy use by life-cycle stages of NGVs and comparable traditional fuel vehicles in China $(\mathrm{C} 1, \mathrm{C} 2, \mathrm{C} 3, \mathrm{C} 4$ and $\mathrm{C} 5$ represent the life-cycle sub-stages, i.e. energy extraction, energy transport, fuel production, fuel transport and fuel use)

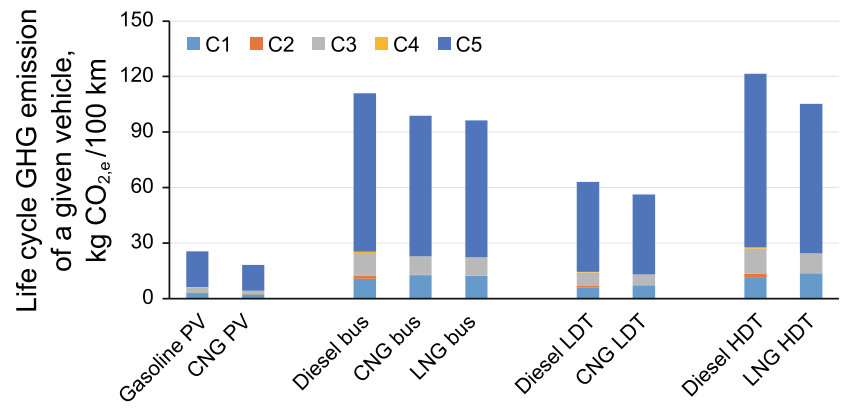

Fig. 10 Life-cycle GHG emissions of NGVs and comparable traditional fuel vehicles in China $(\mathrm{C} 1, \mathrm{C} 2, \mathrm{C} 3, \mathrm{C} 4$ and $\mathrm{C} 5$ represent the life-cycle sub-stages, i.e. energy extraction, energy transport, fuel production, fuel transport and fuel use)

primary energy use of a given CNGV being significantly lower than that of a comparable gasoline vehicle by approximately of $16.3 \%$, the primary energy use of other NGVs is slightly higher than that of comparable diesel vehicles. Moreover, the results indicate that most of the life-cycle primary energy used is NG for NGVs and oil for traditional fuel vehicles, accounting for $92.7 \%$ and $89.6 \%$, respectively. Additionally, it is evident that most of the life-cycle energy use, approximately $77 \%$, occurs during the fuel-use stage for both NGVs and traditional fuel vehicles (see Fig. 9).

\subsection{Life-cycle GHG emissions of NGVs and accompanying GHG emissions reduction benefits}

Figure 10 illustrates the estimated life-cycle GHG emissions of NGVs and comparable traditional fuel vehicles in China. These results suggest that the life-cycle GHG emissions of a given CNGV are significantly lower than those of a comparable gasoline vehicle. An approximate $29.0 \%$ reduction in GHG emissions can be attained in China by replacing a gasoline vehicle with a CNGV. Regarding other types of NGVs, compared to a diesel vehicle, there is also a distinct advantage in GHG emissions with an average of an approximate $12.0 \%$ reduction. 


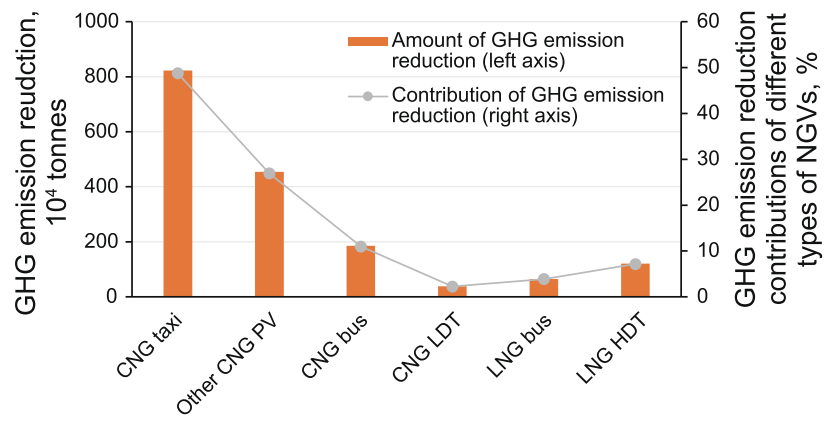

Fig. 11 GHG emissions reduction contributions of classified NGV fleets in China

Moreover, most of the life-cycle GHG emissions, approximately $76 \%$, occur during the fuel-use stage for both NGVs and traditional fuel vehicles. The contribution of classified NGV fleets to GHG emissions reduction in China is presented in Fig. 11. Due to the use of NGVs, the amount of GHG emissions has been significantly reduced. In 2015, the NGV fleet has contributed a GHG emissions reduction of $16.9 \mathrm{Mt}$ of $\mathrm{CO}_{2}$ equivalent, accounting for approximately $1 \%$ of all GHG emissions from on-road vehicles in China (Boden et al. 2016; Energy Information Administration (EIA) of U.S. 2016).

\subsection{Comparison of the results with those of other studies}

As Table 8 indicates, the LCA energy use results of different studies focused on NGVs in China and other countries are compared. For the LNG HDT and LNG bus application types, this study has a relatively pessimistic result, with net energy saving rate (NESR) values of
$-8.4 \%$ and $-9.5 \%$, respectively, but the NESR values of other studies in China are more optimistic, namely greater than zero (Lin et al. 2015; Tu et al. 2013a). For the CNG LDT application type, the result of this study is $-8.6 \%$, a negative result similar to that obtained in other countries such as Canada (Shahraeeni et al. 2015). For the CNG bus application type, among studies specific to China, the current work reports the most optimistic NESR value (Fang 2009; Wang 2015). For the CNG PV application type, all studies (including this study) have similar positive results (Curran et al. 2014; Fang 2009; Ou and Zhang 2013; Wang 2015).

The comparison of the LCA GHG emission results of different studies focused on NGVs in China and other countries is shown in Table 9. For the LNG HDT application type, the value of the net GHG reduction rate (NGRR) in this study is $8 \%$, a positive result similar to that obtained in other studies on China and other countries (Arteconi et al. 2010; Tu et al. 2013b). For the LNG bus application type, the result in this study is $7 \%$, a more pessimistic result than that of other studies specific to China but similar to the findings of studies from other countries (Beer et al. 2002; Ercan and Tatari 2015; Lin et al. 2015). For the CNG LDT application type, the result of this study is $10.4 \%$, which is a more pessimistic result than that obtained for Canada (Shahraeeni et al. 2015). For the CNG bus application type, all studies (including this study) have similar positive results (Beer et al. 2002; Ercan and Tatari 2015; Fang 2009; Wang 2015; Xu et al. 2015). For the CNG PV application type, the studies specific to China (including this study) have similar NGRR figures, but they have a more optimistic result than that found for
Table 8 NGVs' LCA energy use results across studies

\begin{tabular}{lllll}
\hline NGV type & Region & Source & Press time & Net energy saving rate, \% \\
\hline \multirow{2}{*}{ LNG HDT } & China & This study & 2017 & -8.4 \\
& China & Tu et al. (2013a) & 2013 & 6.4 \\
\multirow{2}{*}{ CNG LDT } & China & This study & 2017 & -8.6 \\
& Canada & Shahraeeni et al. (2015) & 2015 & -2 \\
\multirow{5}{*}{ CNG Bus Bus } & China & This study & 2017 & -9.5 \\
& China & Lin et al. (2015) & 2015 & 7.9 \\
& China & This study & 2017 & -9 \\
& China & Wang (2015) & 2015 & -26 \\
CNG PV & China & Fang (2009) & 2009 & -14.6 \\
& China & This study & 2017 & 16.3 \\
& China & Ou and Zhang (2013) & 2013 & 1.9 \\
& China & Wang (2015) & 2015 & 23 \\
& China & Fang (2009) & 2009 & -8.3 to 9 \\
& USA & Curran et al. (2014) & 2014 & 23
\end{tabular}

${ }^{\mathrm{a}} \mathrm{CNG}$ PV in Fang (2009) includes CNG/gasoline-fuelled PV and CNG-fuelled PV 
Table 9 NGVs' LCA GHG emission results across studies

\begin{tabular}{lllll}
\hline NGV type & Region & Source & Press time & Net GHG reduction rate, \% \\
\hline \multirow{2}{*}{ LNG HDT } & China & This study & 2017 & 8 \\
& China & Tu et al. (2013b) & 2013 & 8.9 \\
& Europe & Arteconi et al. (2010) & 2010 & 10 \\
CNG LDT & China & This study & 2017 & 10.4 \\
& Canada & Shahraeeni et al. (2015) & 2015 & 34 \\
LNG Bus & China & This study & 2017 & 7 \\
& China & Lin et al. (2015) & 2015 & 18.3 \\
& USA & Ercan and Tatari (2015) & 2015 & 7.8 \\
& Australia & Beer et al. (2002) & 2002 & 4.9 \\
CNG Bus & China & This study & 2017 & 10 \\
& China & Wang (2015) & 2015 & 8 \\
& China & Fang (2009) & 2009 & 11.4 \\
& USA & Xu et al. (2015) & 2015 & 24 \\
& USA & Ercan and Tatari (2015) & 2015 & 8.4 \\
& Australia & Beer et al. (2002) & 2002 & 9.8 \\
& China & This study & 2017 & 28.8 \\
& China & Ou and Zhang (2013) & 2013 & $10-20$ \\
& China & Wang (2015) & 2015 & 42 \\
& China & Fang (2009) & 2009 & $10.7-26^{\text {a }}$ \\
& USA & Curran et al. (2014) & 2014 & 20.4 \\
\hline
\end{tabular}

${ }^{\mathrm{a}} \mathrm{CNG}$ PV in Fang (2009) includes CNG/gasoline-fuelled PV and CNG-fuelled PV the USA (Curran et al. 2014; Fang 2009; Ou and Zhang 2013; Wang 2015).

Differences between life-cycle energy use and GHG emissions results among studies of NGVs in China and other countries are largely due to (1) the difference in the adopted fuel consumption rate, including the impact of different application types and tonnage types. For example, a study by $\mathrm{Tu}$ et al. (2013b) evaluated the life-cycle emissions of GHGs and other pollutants from NG-powered concrete-mixer trucks, a typical type of truck (Cai et al. 2017; Hao et al. 2015; Song et al. 2017; Tu et al. 2013b); (2) differences in the energy consumption and GHG emissions produced in the process of fuel acquisition, particularly for widely used industry boilers largely fuelled by coal, which have an low efficiency compared with the global level (Cai et al. 2017; Ou et al. 2010; Wang 2015); and (3) different operating environments (Ercan and Tatari 2015; Lajunen and Lipman 2016; Lin et al. 2015).

\subsection{Enhancing the petroleum substitution, greenhouse gas emissions reduction and environmental benefits by increasing the use of NGVs}

If given increased attention from the Chinese government, for example, increasing the efforts to address the pollution from diesel HDTs in the Beijing-Tianjin-Hebei region beginning in 2017 (MEP et al. 2017; NEA et al. 2017), NGVs have a promising future. Based on the issued policies and plans, it is estimated that the population of NGVs in 2020 and 2030 in China will be 8 and 14 million, respectively (CATARC Beijing Operations 2017; Li 2017; NDRC 2016). Accordingly, the accompanying petroleum substitution benefits and CAP and GHG emissions reduction benefits from NGV use in 2020 and 2030 in China are presented in Figs. 12, 13, 14. The NG consumption of NGVs in 2020 and 2030 in China is estimated to be 51.1 and 99.1 billion $\mathrm{m}^{3}$, respectively. In 2020, the accompanying petroleum substitution benefits and CAP and GHG emissions reduction benefits from increasing the use of NGVs in China will be $42.5 \mathrm{Mt}$ of petroleum-based fuel, 3.1 Mt of CAPs and 28.0 Mt of GHGs, respectively. By 2030, 81.5 Mt of traditional petroleum fuel will be reduced, and an emissions reduction of 5.6 Mt of CAPs and $50.5 \mathrm{Mt}$ of GHGs will be achieved.

\section{Concluding remarks}

This study develops a bottom-up model for NGV fleets in China and conducts an LCA with a combination of realtime fuel economy data, actual vehicle population data and a life-cycle inventory database from the TLCAM specified for the context of China. A comparative study on the direct 


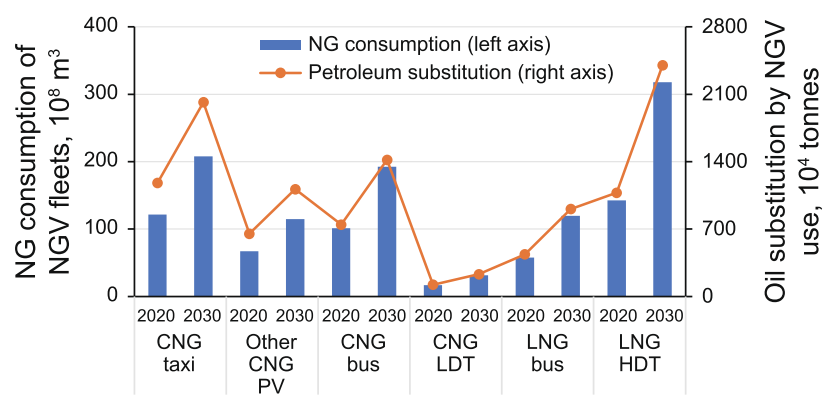

Fig. 12 NG consumption of classified NGV fleets and accompanying petroleum substitution in 2020 and 2030

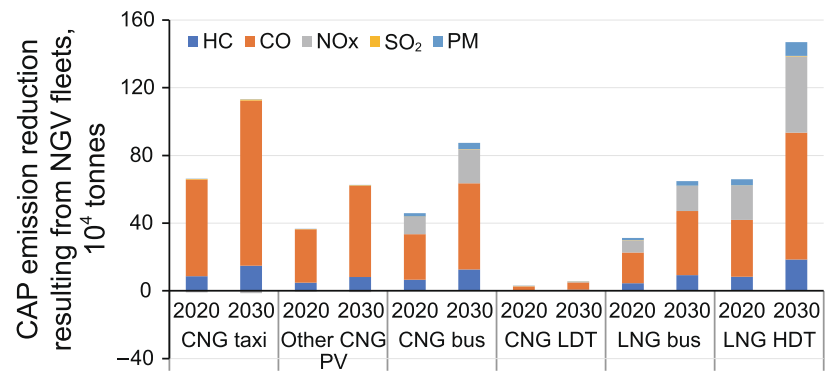

Fig. $13 \mathrm{CAP}$ emission reduction resulting from classified NGV fleets in 2020 and 2030

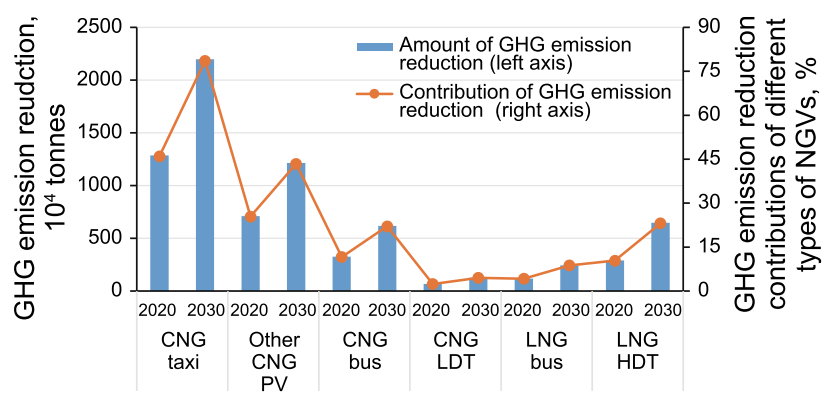

Fig. 14 GHG emissions reduction contributions of classified NGV fleets in China in 2020 and 2030

energy consumption, life-cycle energy use, direct CAP emissions and life-cycle GHG emissions intensity of NGVs and comparable traditional fuel vehicles in China is conducted. Based on this analysis, the comprehensive effects of replacing traditional petroleum fuel powered vehicles with NGVs in China, including the petroleum substitution benefit, CAP reduction benefit and GHG reduction benefit, are investigated.

Our findings indicate that on average, there are no net energy savings from replacing a traditional fuel vehicle with an NGV. Therefore, appropriate measures need to be taken to improve transportation system efficiency based on the resources consumed. Interestingly, an NG-powered vehicle results in significant direct CAP and life-cycle GHG emissions reductions compared to that of a traditional fuel vehicle, ranging from $61 \%$ to $76 \%$ and ranging from $12 \%$ to $29 \%$, respectively. An NGV results in significant reductions in petroleum consumption compared to a gasoline/diesel vehicle, ranging from 1.2 to 8.9 tonnes and 20.3-40.8 tonnes, respectively. Due to the increasing use of natural gas as a vehicle fuel in China (i.e. approximately 28.2 billion cubic metres of natural gas in 2015), the total gasoline/diesel fuel substituted with natural gas was approximately $23.8 \mathrm{Mt}$, which generated a GHG emissions reduction of $16.9 \mathrm{Mt}$ of $\mathrm{CO}_{2}$ equivalent and a CAP emissions reduction of $1.8 \mathrm{Mt}$ in 2015. Given the significant contribution of NGVs, growing the NGV population in 2020 will further increase the petroleum substitution benefits and CAP and GHG emissions reduction benefits by approximately $3.1 \mathrm{Mt}$ of CAPs and 28.0 Mt of GHGs, respectively. By 2030 , these benefits will reach $81.5 \mathrm{Mt}$ of traditional fuel, 5.6 Mt of CAPs and 50.5 Mt of GHGs, representing a significant contribution to energy security and emissions reduction for China. Therefore, China should increase its efforts to promote the use of NGVs to replace traditional fuel vehicles.

Because the use of NGVs contributes significantly to reducing CAP and GHG emissions, increasing the share of NGVs in the vehicle market can play an important role in improving air quality and addressing climate change. To achieve this target, potential solutions should be developed by considering three perspectives: NGV enterprises, governmental departments and public consumers. NGV enterprises should enhance the research and development of NGVs. Consistent development will not only increase the energy economy of the produced vehicles but will also improve their quality. This progress will further reduce pollutant emissions, reduce maintenance costs and even reduce purchase and modification costs. To accelerate the development of NGVs, governmental departments must provide effective policy support in terms of making NG prices competitive with petroleum-based fuel prices, promoting NG infrastructure construction, providing purchase subsidies, offering highway fee concessions and enhancing the environmental requirements of NGVs ( $\mathrm{Li}$ et al. 2015; $\mathrm{Wu}$ et al. 2016; Zheng et al. 2015). Moreover, to better stimulate the development of NGVs, different countermeasures need to be implemented that take into account the different circumstances in different provinces (CATARC Beijing Operations 2017). Furthermore, increasing the awareness of public consumers regarding the positive environmental impacts and the cost-effectiveness of NGVs compared to traditional fuel vehicles is very important. If more consumers understand that NGVs are affordable and environmentally friendly, more NGVs will be sold, which will increase the use of NGVs. 
Acknowledgements This study was co-sponsored by the National Natural Science Foundation of China (71774095, 71690244 and 71673165), the Postdoctoral Science Foundation of China (2017M610096) and the International Science and Technology Cooperation Program of China (2016YFE0102200).

Open Access This article is distributed under the terms of the Creative Commons Attribution 4.0 International License (http://creative commons.org/licenses/by/4.0/), which permits unrestricted use, distribution, and reproduction in any medium, provided you give appropriate credit to the original author(s) and the source, provide a link to the Creative Commons license, and indicate if changes were made.

\section{References}

Arteconi A, Brandoni C, Evangelista D, et al. Life-cycle greenhouse gas analysis of LNG as a heavy vehicle fuel in Europe. Appl Energy. 2010;87(6):2005-13. https://doi.org/10.1016/j.apenergy. 2009.11.012.

Beer T, Grant T, Williams D, et al. Fuel-cycle greenhouse gas emissions from alternative fuels in Australian heavy vehicles. Atmos Environ. 2002;36(4):753-63. https://doi.org/10.1016/ S13522310(01)00514-3.

Boden TA, Marland G, Andres RJ. Global, regional, and national fossil-fuel $\mathrm{CO}_{2}$ emissions. Oak Ridge: Carbon Dioxide Information Analysis Center, Oak Ridge National Laboratory, U.S. Department of Energy; 2016.

British Petroleum (BP). BP statistical review of world energy 2016. London: BP; 2016.

Cai H, Burnham A, Chen R, et al. Wells to wheels: environmental implications of natural gas as a transportation fuel. Energy Policy. 2017;109:565-78. https://doi.org/10.1016/j.enpol.2017. 07.041 .

China Automotive Technology and Research Center (CATARC) Beijing Operations. Research report on the development of natural gas vehicle industry in China. Beijing: CATARC Beijing Operations; 2017 (in Chinese).

China National Petroleum Corporation (CNPC) Economics \& Technology Research Institute (ETRI). Research on the industry of natural gas vehicles in China in 2015. Beijing: CNPC ETRI; 2016 (in Chinese).

Curran SC, Wagner RM, Graves RL, et al. Well-to-wheel analysis of direct and indirect use of natural gas in passenger vehicles. Energy. 2014;75:194-203. https://doi.org/10.1016/j.energy. 2014.07.035.

Energy Information Administration (EIA) of U.S. International energy outlook 2016. Washington DC: EIA; 2016.

Ercan T, Tatari O. A hybrid life cycle assessment of public transportation buses with alternative fuel options. Int $\mathrm{J}$ Life Cycle Assess. 2015;20:1213-31. https://doi.org/10.1007/s11367015-0927-2.

Fang JR. Analysis and assessment of energy and environmental benefits of new energy vehicles. Changchun: Jilin University; 2009 (in Chinese).

Huo H, Wang M, Zhang XL, et al. Projection of energy use and greenhouse gas emissions by motor vehicles in China: policy options and impacts. Energy Policy. 2012;43(3):37-48. https:// doi.org/10.1016/j.enpol.2011.09.065.

Hao H, Wang HW, Ouyang MG. Fuel consumption and life cycle GHG emissions by China's on-road trucks: future trends through 2050 and evaluation of mitigation measures. Energy Policy. 2013;43:244-51. https://doi.org/10.1016/j.enpol.2011.12.061.
Hao H, Geng Y, Li WQ, et al. Energy consumption and GHG emissions from China's freight transport sector: scenarios through 2050. Energy Policy. 2015;85:94-101. https://doi.org/ 10.1016/j.enpol.2015.05.016.

Hao H, Liu ZW, Zhao FQ, et al. Natural gas as vehicle fuel in China: a review. Renew Sustain Energy Rev. 2016;62:521-33. https:// doi.org/10.1016/j.rser.2016.05.015.

Intergovernmental Panel on Climate Change (IPCC). IPCC fourth assessment report: climate change 2007. Oxford: Oxford Publisher; 2007. p. 2007.

International Energy Agency (IEA). World energy outlook special report-energy and air pollution. Paris: IEA; 2016. p. 2016.

IEA. World energy outlook special report-energy and climate change. Paris: IEA; 2015. p. 2015.

Jiao JL, Zuo FF, Li LL, et al. Estimation of China's alternative policies of automotive fuels - a perspective of oil dependence. J Clean Prod. 2017;161:698-707. https://doi.org/10.1016/j.jcle pro.2017.05.107.

Khan MI, Yasmin T, Shakoor A. Technical overview of compressed natural gas (CNG) as a transportation fuel. Renew Sustain Energy Rev. 2015;51:785-97. https://doi.org/10.1016/j.rser. 2015.06.053.

Kliucininkas L, Matulevicius J, Martuzevicius D. The life cycle assessment of alternative fuel chains for urban buses and trolleybuses. J Environ Manag. 2012;99:98-103. https://doi. org/10.1016/j.jenvman.2012.01.012.

Lajunen A, Lipman T. Lifecycle cost assessment and carbon dioxide emissions of diesel, natural gas, hybrid electric, fuel cell hybrid and electric transit buses. Energy. 2016;106:329-42. https://doi. org/10.1016/j.energy.2016.03.075.

$\mathrm{Li} \mathrm{YC}$. Analysis of the latest information and hot issues of natural gas vehicles in China. In: 2017 International Symposium on innovation development of natural gas vehicles and vessels, Beijing; 2017 (in Chinese).

Li WQ, Dai YP, Ma LW, et al. Oil-saving pathways until 2030 for road freight transportation in China based on a cost-optimization model. Energy. 2015;86:369-84. https://doi.org/10.1016/j. energy.2015.04.033.

Lin XD, Lü B, Tian L, et al. Analysis of energy conservation and greenhouse gas emissions reduction potential of buses in Beijing city based on life cycle assessment. Acta Sci Circum. 2015;35(2):576-84. https://doi.org/10.13671/j.hjkxxb.2014.0872 (in Chinese).

Ma YF, Li YL. Analysis of the supply-demand status of China's natural gas to 2020. Pet Sci. 2010;7(1):132-5. https://doi.org/10. 1007/s12182-010-0017-9.

Ma LW, Geng J, Li WQ, et al. The development of natural gas as an automotive fuel in China. Energy Policy. 2013;62:531-9. https:// doi.org/10.1016/j.enpol.2013.06.066.

Ministry of Environmental Protection (MEP). China vehicle environmental management annual report in 2016. Beijing: MEP; 2017a (in Chinese).

Ministry of Environmental Protection (MEP). China vehicle emission control annual report in 2016. Beijing: MEP; 2017b (in Chinese).

MEP, National Development and Reform Commission (NDRC), Ministry of Finance (MOF) of China. The action plan on air pollution prevention and control in the Beijing-Tianjin-Hebei region and the surrounding areas in 2017. Beijing: MEP; 2017 (in Chinese).

National Bureau of Statistics (NBS). China energy statistical yearbook. Beijing: China Statistics Press; 2016.

NDRC. The national plan on climate change (2014-2020). Beijing: NDRC; 2014 (in Chinese).

NDRC. The 13th five-year plan for natural gas development. Beijing: NDRC; 2016 (in Chinese). 
NDRC, Ministry of Science and Technology (MOST), Ministry of Industry and Information Technology (MIIT), et al. The opinions on accelerating the utilization of natural gas. Beijing: NDRC; 2017 (in Chinese).

NDRC, National Energy Administration (NEA). The 13th five-year plan for energy development. Beijing: NDRC and NEA; 2016a (in Chinese).

NDRC, National Energy Administration (NEA). The strategy for energy production and consumer revolution (2016-2030). Beijing: NDRC and NEA; 2016b (in Chinese).

NEA, Development Research Center of State Council (SC), Ministry of Land and Resources (MLR). China natural gas development report in 2017. Beijing: Petroleum Industry Press; 2017 (in Chinese).

NGV Global. Current natural gas vehicle statistics. http://www.iangv. org/current-ngv-stats (2017). Accessed 25 July 2017.

Niu L, Wang BC, Yan M, et al. Analyze impact of replaceable energy development on China's petroleum demand. Oil Forum. 2017;3:7-15. https://doi.org/10.3969/j.issn.1002-302x.2017.03. 002.

Osorio-Tejada J, Llera E, Scarpellini S. LNG: an alternative fuel for road freight transport in Europe. Sustain Dev. 2015;1:235-46. https://doi.org/10.2495/SD150211.

Ou XM, Zhang XL. Life-cycle analyses of energy consumption and GHG emissions of natural gas-based alternative vehicle fuels in China. J Energy. 2013;2013:1-8. https://doi.org/10.1155/2013/ 268263.

Ou XM, Zhang XM, Chang SY. Alternative fuel buses currently in use in China: life-cycle fossil energy use, GHG emissions and policy recommendations. Energy Policy. 2010;38(1):406-18. https://doi.org/10.1016/j.enpol.2009.09.031.

Ou XM, Yan XY, Zhang XL, et al. Life-cycle analysis on energy consumption and GHG emission intensities of alternative vehicle fuels in China. Appl Energy. 2012;90(1):218-24. https://doi.org/ 10.1016/j.apenergy.2011.03.032.

Ou XM, Zhang XL, Zhang X, et al. Life cycle GHG of NG-based fuel and electric vehicle in China. Energies. 2013;6(5):2644-62. https://doi.org/10.3390/en6052644.

Rose L, Hussain M, Ahmed S, et al. A comparative life cycle assessment of diesel and compressed natural gas powered refuse collection vehicles in a Canadian city. Energy Policy. 2013;52:453-61. https://doi.org/10.1016/j.enpol.2012.09.064.

Shahraeeni M, Ahmed A, Malek K, Van Drimmelen B, Kjeang E. Life cycle emissions and cost of transportation systems: case study on diesel and natural gas for light duty trucks in municipal fleet operations. J Nat Gas Sci Eng. 2015;24:26-34. https://doi. org/10.1016/j.jngse.2015.03.009.

Shen W, Han WJ, Chock D, et al. Well-to-wheels life-cycle analysis of alternative fuels and vehicle technologies in China. Energy Policy. 2012;49(1):296-307. https://doi.org/10.1016/j.enpol. 2012.06.038.

Song $\mathrm{HQ}, \mathrm{Ou} \mathrm{XM}$, Yuan $\mathrm{JH}$, et al. Energy consumption and greenhouse gas emissions of diesel/LNG heavy-duty vehicle fleets in China based on a bottom-up model analysis. Energy. 2017;140:966-78. https://doi.org/10.1016/j.energy.2017.09.011.

SC. The action plan for air pollution prevention and control. Beijing: SC; 2013 (in Chinese).

SC. The strategy action plan for energy development (2014-2020). Beijing: SC; 2014 (in Chinese).

SC. The comprehensive work plan for energy conservation and emission reduction during the 13th five year plan period. Beijing: SC; 2017 (in Chinese).

Tu XY, Xu JQ, Chen YS, et al. An evaluation of differences between LNG and diesel commercial vehicle's life cycle energy consumption. China Mech Eng. 2013a;24(23):3211-5. https:// doi.org/10.3969/j.issn.1004-132X.2013.23.018.

Tu XY, Yang YP, Xu JQ, et al. Evaluation of differences between LNG and diesel heavy-duty vehicle's life cycle environmental emission. China Mech Eng. 2013b;24(11):1425-30. https://doi. org/10.3969/j.issn.1004-132X.2013.11.021 (in Chinese).

Wang RJ. Fuel-cycle assessment of energy and environmental impacts from electric vehicles and natural gas vehicles. Beijing: Tsinghua University; 2015 (in Chinese).

Wu XM, Wu Y, Zhang SJ, et al. Assessment of vehicle emission programs in China during 1998-2013: achievement, challenges and implications. Environ Pollut. 2016;214:556-67. https://doi. org/10.1016/j.envpol.2016.04.042.

Xing Y, Song HQ, Yu MX, et al. The characteristics of greenhouse gas emissions from heavy-duty trucks in the Beijing-TianjinHebei (BTH) region in China. Atmosphere. 2016;7(9):121. https://doi.org/10.3390/atmos7090121.

$\mathrm{Xu}$ YZ, Gbologah FE, Lee DY, et al. Assessment of alternative fuel and powertrain transit bus options using real-world operations data: life-cycle fuel and emissions modeling. Appl Energy. 2015;154:143-59. https://doi.org/10.1016/j.apenergy.2015.04. 112.

Yang X, Teng F. The air quality co-benefit of coal control strategy in China. Resour Conserv Recycl. 2018;129:373-82. https://doi. org/10.1016/j.resconrec.2016.08.011.

Yang X, Wan H, Zhang Q, et al. A scenario analysis of oil and gas consumption in China to 2030 considering the peak $\mathrm{CO}_{2}$ emission constraint. Pet Sci. 2016;13(2):370-83. https://doi. org/10.1007/s12182-016-0089-2.

Yao SF, Liu ZR, Yuan CM, et al. Comprehensive evaluation of CNG auto industry development in Sichuan Province. J Xihua Univ (Nat Sci ed). 2009;28(6):74-9. https://doi.org/10.3969/j.issn. 1673-159X.2009.06.019.

Yun J, Qin GJ, Wang JL, et al. Model and methods for comprehensive measurement of the low-carbon status of China's oil and gas enterprises. Pet Sci. 2012;9(2):262-8. https://doi.org/10.1007/ s12182-012-0208-7.

Zheng B, Zhang Q, Borken-Kleefeld J, et al. How will greenhouse gas emissions from motor vehicles be constrained in China around 2030? Appl Energy. 2015;156:230-40. https://doi.org/10.1016/j. apenergy.2015.07.018. 